\title{
The influence of quality of life on the level of adherence to therapeutic recommendations among elderly hypertensive patients
}

This article was published in the following Dove Press journal:

Patient Preference and Adherence

\author{
Bartosz Uchmanowicz' \\ Anna Chudiak' \\ Grzegorz Mazur² \\ 'Department of Clinical Nursing, \\ Faculty of Health Sciences, Wroclaw \\ Medical University, Wroclaw, Poland; \\ ${ }^{2}$ Department and Clinic of Internal \\ and Occupational Diseases and \\ Hypertension, Faculty of Medicine, \\ Wroclaw Medical University, \\ Wroclaw, Poland
}

Background: Hypertension is one of the most important risk factors for cardiovascular disease, which contributes to lowering the quality of life (QOL), especially in elderly patients. Recent data show that almost half of the hypertensive patients and one-third of patients with comorbidities were nonadherent to medication.

Objective: To assess the association of QOL with the level of adherence and to examine the association with selected variables on the level of adherence.

Design: A prospective, cross-sectional, and analytical study.

Methods: This study involved 186 hypertensive elderly patients (mean age: $71.05 \pm 7.47$ years). An analysis of medical records based on sociodemographic and clinical data was conducted. The World Health Organization Quality of Life Scale Brief version (WHOQOL-BREF) was used to assess the level of QOL, and the Hill-Bone Compliance to High Blood Pressure Therapy Scale (HBQ) was used to examine the level of adherence to therapeutic recommendations in hypertensive patients. Results: The average assessment of the QOL measured by the WHOQOL-BREF questionnaire was $3.36 \pm 0.84$ points, which indicates a QOL at a level between average and good. The patients' average score on the HBQ questionnaire was $20.39 \pm 4.31$ points. In the "reduced sodium intake" subscale, patients had an average of $4.75 \pm 1.33$ points. In the "appointment keeping" subscale, the patients scored an average of $3.45 \pm 1.07$ points. In the "medication taking" subscale, the patients had an average of $12.19 \pm 3.46$ points. It was shown that the total score of the HBQ questionnaire was negatively correlated with all domains of QOL assessed with the WHOQOL-BREF questionnaire $(P<0.05)$. Conclusion: There is an association between QOL and adherence to therapeutic recommendations among hypertensive elderly patients. It has been concluded that with an increasing QOL, the level of adherence to therapeutic recommendations increases. The level of adherence is also negatively affected by: older age, longer duration of disease, worse marital status, lower education, living alone, and using polytherapy.

Keywords: hypertension, adherence, elderly patients, WHOQOL-BREF questionnaire, HillBone Compliance questionnaire, cross-sectional study

\section{Introduction}

Hypertension, one of the most important risk factors for cardiovascular disease, includes coronary artery disease, heart failure, and cerebral stroke. These diseases are among the main causes of mortality, morbidity, and disability in Poland and throughout the world. ${ }^{1}$ It has been confirmed that an increase in systolic blood pressure by $20 \mathrm{mmHg}$ and diastolic blood pressure by $10 \mathrm{mmHg}$ doubles the risk of death. ${ }^{2}$

The estimated global prevalence of hypertension in adults aged $>20$ years is $31.1 \%$, with $31.9 \%$ in men and $30.1 \%$ in women. ${ }^{3}$ The baseline age-standardized prevalence 
of hypertension is $74.3 \%$ for men and $70.2 \%$ for women aged 45-83 years. ${ }^{4}$ Polish epidemiological data show that hypertension affects $42 \%$ of people between 35 and 64 years of age, and the number increases to $60 \%$ in those over 60 years of age. ${ }^{5}$ The prevalence of hypertension increases with age, regardless of gender, affecting $70 \%$ of the general population over the age of $80.6,7$

The epidemiological consequences of hypertension are undeniable and lead to further discussion in the context of health care. Despite the medical progress that has been made in the field of treatment, the effectiveness of antihypertensive therapy is still disturbingly low. Appropriate control of blood pressure is currently obtained only by about $15 \%-20 \%$ of patients. ${ }^{8}$ Only $10 \%$ of patients who report taking antihypertensive drugs attain advantageous blood pressure values. ${ }^{9}$

The main reason for poor treatment effectiveness is failure to adhere to therapeutic recommendations, referred to as "non-adherence." In addition, some patients do not take antihypertensive drugs according to recommendations from health professionals, which leads to ineffective therapy. ${ }^{10}$ The latest meta-analysis shows that a significant number (45.2\%) of hypertensive patients and one-third (31.2\%) of patients with comorbidities were nonadherent to medication. ${ }^{11}$ The costs of nonadherence to medication are both personal and economic; it is estimated that approximately $8 \%$ of global total health costs could be avoided by adhering to treatment recommendations. ${ }^{12}$

Many reasons exist for this phenomenon, including the psychological and physiological aspects related to the aging of the body (cognitive impairment, polypharmacy, frailty syndrome, depressed mood, problems with sight and hearing). ${ }^{13}$ Among the reasons mentioned are health-related factors addressed by the therapeutic team and objective factors related to the availability of benefits and the function of the health care system. ${ }^{14}$ The quality of life (QOL) of elderly patients struggling with chronic disease is not without significance. Recent data indicate that hypertension contributes to lowering the QOL of patients as compared to normotensive patients. ${ }^{15}$

The QOL of people with hypertension is affected by issues related to the very existence of the disease and its chronic nature; the diagnosis of the disease; its negative impact on the patient's physical, emotional and social wellbeing; and aspects related to pharmacological treatment. ${ }^{16,17}$

Identification of the causes of reduced QOL and its consequences include nonadherence to therapeutic recommendations and the implementation of approaches used to increase the effectiveness of antihypertensive therapy and thus to reduce mortality and morbidity. Available studies suggest that appropriate QOL can contribute to the satisfactory effects of antihypertensive treatment. ${ }^{18,19}$

The objective of the study was to assess the association of QOL with the level of adherence to the therapeutic recommendations among elderly hypertensive patients and to examine the association with selected variables on the level of adherence.

\section{Materials and methods Study participants}

This study involved 186 hypertensive elderly patients (102 women and 84 men) attending a general practitioners at the Clinic of Hypertension in Wroclaw, Poland. The mean patients' age was 71.05 years $(\mathrm{SD}=7.47$ years; median=67 years) and the mean duration of hypertension was 13.55 years $(\mathrm{SD}=8.71$ years; median $=12$ years $)$.

\section{Qualification criteria}

The inclusion criteria were: 1) a diagnosis of hypertension based on the guidelines of the Polish Society of Hypertension, ${ }^{20}$ 2) hypertension lasting longer than 12 months, 3) the patient's age 65 years of age or older, 4) hypertension treated pharmacologically with at least one antihypertensive drug, 5) the lack of cognitive impairment based on scores from the Mini-Mental State Examination (MMSE) or during the interview procedure, and 6) the written informed consent document indicating their voluntary participation in the study. The exclusion criteria were the opposite of the abovementioned list.

\section{Research tools}

An analysis of medical records was conducted to obtain necessary sociodemographic and clinical data. The World Health Organization Quality of Life Scale Brief version (WHOQOL-BREF) was used to assess the level of QOL, and the Hill-Bone Compliance to High Blood Pressure Therapy Scale (HBQ), a questionnaire earmarked for patients with hypertension, was used to examine the level of adherence to therapeutic recommendations.

The WHOQOL-BREF is the short version of the WHOQOL-100 questionnaire and allows the researcher to evaluate QOL in six dimensions. In the first two dimensions (perception of QOL and perception of health), QOL is expressed on a scale of 1-5 and in the other dimensions (physical, social, psychological, environmental), QOL is expressed on a scale of 4-20. The higher the respondent's total score, the better the QOL. ${ }^{21}$ The questionnaire was translated and adapted to Polish conditions by Wolowicka and Jaracz. ${ }^{22}$ 
The HBQ assesses the patient's adherence to antihypertensive therapy treatment recommendations and is comprised of 14 questions with a total score of $14-56$ points. Because each of the three subscales contains a different number of questions, each scale has a different range of values. The subscale "reduced sodium intake" contains three questions (a range of 3-12 points), the subscale "appointment keeping" contains two questions (a range of 2-8 points), and the subscale "medication taking" contains nine questions (a range of 9-36 points). The higher the number of points, the more often the adherence is violated (low adherence). There are no referral values to determine how many points indicate a good level of adherence to therapeutic recommendations and how many indicate a bad level (non-adherence). ${ }^{23}$ The adaptation to Polish conditions was made by Uchmanowicz et al. ${ }^{24}$

\section{Ethical considerations}

The study was approved by the independent Bioethics Committee of the Wroclaw Medical University, Poland (approval no KB-114/2016). All patients signed witnessed informed consent forms and were aware of all their rights including the right to withdraw from the study at any stage of the investigation. The study was carried out in accordance with the tenets of the Declaration of Helsinki and guidelines of the Good Clinical Practice.

\section{Statistical analysis}

The R software version 3.5.0 (R Development Core Team, Auckland, New Zealand) was used to perform data analysis. The Shapiro-Wilk test was used to check the normality of variables distribution. Medians and quartiles (Q1-Q3) of distributions of particular variables were given. The MannWhitney test was used to calculate the comparison between two groups. The Kruskal-Wallis test was used to calculate the comparison between three or more groups. The Dunn test was used to perform a post-hoc analysis if statistically significant differences were detected. The Spearman rank correlation coefficient was used to analyze correlations. Multivariate analysis of the independent influence of many variables on the numerical variable was analyzed by linear regression $\mathrm{B}^{2}$. The results are presented in the form of the parameter values of a regression model with a $95 \% \mathrm{CI}$. All statistical tests were considered significant with a $P<0.05$.

\section{Results}

The present study was conducted on the sample of 186 elderly patients (102 women and 84 men) with hypertension, aged from 65 to 76 years (mean=71.05 years; $\mathrm{SD}=7.47$ years).
The duration of the disease ranged from 7 to 17 years (mean=13.55 years; $\mathrm{SD}=8.71$ years). Detailed sociodemographic and clinical data are presented in Table 1.

\section{Assessment of QOL using the WHOQOL-BREF questionnaire}

The average assessment of the QOL measured by the WHOQOLBREF questionnaire was 3.36 points ( $\mathrm{SD}=0.84$ points), which shows an association between the QOL in average and good levels. The average patients' assessment of the perception of health was 3.04 points ( $\mathrm{SD}=1.0$ point), which means that

Table I Basic clinical and sociodemographic data of study respondents

\begin{tabular}{|c|c|c|}
\hline Feature & Mean (SD) & Median (QI-Q3) \\
\hline Age, years & $71 . I(7.5)$ & $67(65-76)$ \\
\hline $\mathrm{SBP}, \mathrm{mmHg}$ & $143.6(19)$ & $140(130-150)$ \\
\hline DBP, $\mathrm{mmHg}$ & $86.4(14.6)$ & $90(80-90)$ \\
\hline Disease duration (years) & $13.6(8.7)$ & $12(7-17)$ \\
\hline Feature & $n$ & $\%$ \\
\hline \multicolumn{3}{|l|}{ Sex } \\
\hline Female & 102 & 54.8 \\
\hline Male & 84 & 45.2 \\
\hline \multicolumn{3}{|l|}{ Marital status } \\
\hline Married/living together & 105 & 56.5 \\
\hline Single/divorced & 18 & 9.7 \\
\hline Widowed & 63 & 33.9 \\
\hline \multicolumn{3}{|l|}{ Education } \\
\hline None/primary & 50 & 26.9 \\
\hline Secondary & 86 & 46.2 \\
\hline Vocational/higher & 50 & 26.9 \\
\hline \multicolumn{3}{|l|}{ Occupational activity } \\
\hline Employed & 26 & 14 \\
\hline Retired & 129 & 69.4 \\
\hline Annuitant & 31 & 16.7 \\
\hline \multicolumn{3}{|l|}{ Place of residence } \\
\hline $\begin{array}{l}\text { Living alone/in an organized } \\
\text { institution }\end{array}$ & 55 & 29.6 \\
\hline Living with family & 131 & 70.4 \\
\hline \multicolumn{3}{|l|}{ Comorbidities } \\
\hline Diabetes & 102 & 54.8 \\
\hline Hypercholesterolemia & 60 & 32.3 \\
\hline Coronary artery disease & 52 & 28 \\
\hline Renal failure & 27 & 14.5 \\
\hline Rheumatic diseases & 32 & 17.2 \\
\hline \multicolumn{3}{|l|}{ Therapy } \\
\hline Monotherapy & 84 & 45.2 \\
\hline Polytherapy & 102 & 54.8 \\
\hline
\end{tabular}

Abbreviations: BMI, body mass index; DBP, diastolic blood pressure; $n$, number of patients; QI, first quartile; Q3, third quartile; SBP, systolic blood pressure. 
Table 2 Evaluation of the QOL and each domains using the WHOQOL-BREF as well as evaluation of treatment adherence and each subscale using the HBQ $(n=186)$

\begin{tabular}{|c|c|c|c|c|c|}
\hline WHOQOL-BREF & Mean & SD & Median & QI & Q3 \\
\hline Perception of QOL & 3.36 & 0.84 & 3 & 3 & 4 \\
\hline Perception of health & 3.04 & 1 & 3 & 2 & 4 \\
\hline Physical domain & 13.01 & 2.68 & 13 & 11 & 14.75 \\
\hline Psychological domain & 14.6 & 2.58 & 15 & 13 & 16 \\
\hline Social domain & 14.38 & 2.82 & 15 & 12.25 & 16 \\
\hline Environmental domain & 14.46 & 2.41 & 14 & 12.25 & 16 \\
\hline HBQ & Mean & SD & Median & QI & Q3 \\
\hline Total score & 20.39 & 4.31 & 19.5 & 17 & 22 \\
\hline Reduced sodium intake & 4.75 & 1.33 & 4 & 4 & 5 \\
\hline Appointment keeping & 3.45 & 1.07 & 3.5 & 3 & 4 \\
\hline Medication taking & 12.19 & 3.46 & 11 & 10 & 14 \\
\hline
\end{tabular}

Abbreviations: $\mathrm{HBQ}$, the Hill-Bone Compliance to High Blood Pressure Therapy Scale questionnaire; $n$, number of patients; QI, first quartile; Q3, third quartile; QOL, quality of life; WHOQOL-BREF, the World Health Organization Quality of Life Scale Brief version.

patients scored their health as average (neither satisfactory nor unsatisfactory). The patients considered their QOL most accurately in the psychological domain; their assessment was slightly worse in the environmental and social domains, and worst in the physical domain, with average scores of 14.6, 14.46, 14.38, and 13.01 points, respectively (Table 2).

\section{Evaluation of adherence using the $\mathrm{HBQ}$ questionnaire}

The patients' average score on the HBQ questionnaire was 20.39 ( $\mathrm{SD}=4.31$ points) and ranged from 14 to 34 . In the "Reduced sodium intake" subscale, patients had an average of 4.75 points ( $\mathrm{SD}=1.33$ points). In the "appointment keeping" subscale, the patients scored an average of 3.45 points ( $\mathrm{SD}=1.07$ points). In the "medication taking" subscale, the patients had an average of 12.19 points ( $\mathrm{SD}=3.46$ points). In analyzing the results, it was found that the patients most often stopped the adherence regarding appointment keeping, and least often broke the rules about taking medications (Table 2).

\section{QOL and adherence to therapeutic recommendations}

When analyzing the associations between QOL and the level of adherence, it was shown that the total score of the HBQ questionnaire was negatively correlated with all domains of QOL assessed with the WHOQOL-BREF questionnaire. This means that the frequency of breaking the regimen of therapy decreases with the increase of the QOL $(P<0.05)$ In addition, the frequency of breaking the recommendations regarding the reduced sodium intake is negatively correlated with the perception of the patient's health and both social and environmental domains in the WHOQOL-BREF questionnaire $(P<0.05)$. The frequency of noncompliance regarding appointment keeping and medication taking negatively correlates with all areas of QOL $(P<0.05)$ (Table 3$)$.

The correlation coefficients between the analyzed variables are shown graphically by the heat maps, where negative, left-sided dark areas indicate strong positive correlations and positive, right-sided dark areas indicate strong negative correlations. Light and white areas indicate weakness and a lack of correlation (Figure 1).

Table 3 The correlation coefficient between the results of the HBQ and WHOQOL-BREF as well as between results of the HBQ and chosen qualitative sociodemographic features

\begin{tabular}{|c|c|c|c|c|c|c|}
\hline \multirow[t]{2}{*}{ HBQ } & \multicolumn{6}{|c|}{ Correlation coefficient ${ }^{a}$} \\
\hline & $\begin{array}{l}\text { Perception } \\
\text { of QOL }\end{array}$ & $\begin{array}{l}\text { Perception } \\
\text { of health }\end{array}$ & $\begin{array}{l}\text { Physical } \\
\text { domain }\end{array}$ & $\begin{array}{l}\text { Psychological } \\
\text { domain }\end{array}$ & $\begin{array}{l}\text { Social } \\
\text { domain }\end{array}$ & $\begin{array}{l}\text { Environmental } \\
\text { domain }\end{array}$ \\
\hline Total score & $-0.492^{b}$ & $-0.391^{\mathrm{b}}$ & $-0.381^{b}$ & $-0.528^{b}$ & $-0.434^{b}$ & $-0.489^{b}$ \\
\hline Reduced sodium intake & -0.045 & $-0.154^{b}$ & -0.03 & -0.123 & $-0.161^{b}$ & $-0.181^{b}$ \\
\hline Appointment keeping & $-0.419^{b}$ & $-0.268^{b}$ & $-0.221^{b}$ & $-0.356^{b}$ & $-0.283^{b}$ & $-0.341^{b}$ \\
\hline Medication taking & $-0.5 I^{b}$ & $-0.356^{b}$ & $-0.423^{b}$ & $-0.52^{\mathrm{b}}$ & $-0.409^{\mathrm{b}}$ & $-0.445^{b}$ \\
\hline \multirow[t]{2}{*}{ HBQ } & \multicolumn{6}{|c|}{ Correlation coefficient ${ }^{a}$} \\
\hline & \multicolumn{3}{|l|}{ Age, years } & \multicolumn{3}{|c|}{ Duration of disease, years } \\
\hline Total score & \multicolumn{3}{|l|}{$0.357^{\mathrm{b}}$} & \multicolumn{3}{|l|}{$0.205^{b}$} \\
\hline Reduced sodium intake & \multicolumn{3}{|l|}{0.049} & \multicolumn{3}{|l|}{-0.029} \\
\hline Appointment keeping & \multicolumn{3}{|l|}{0.139} & \multicolumn{3}{|l|}{$0.147^{b}$} \\
\hline Medication taking & \multicolumn{3}{|l|}{$0.296^{b}$} & \multicolumn{3}{|l|}{$0.199^{b}$} \\
\hline
\end{tabular}

Notes: a'Spearman's rank correlation coefficient (non-normal distributions of correlated variables). 'btatistical significance for $P<0.05$.

Abbreviations: HBQ, the Hill-Bone Compliance to High Blood Pressure Therapy Scale questionnaire; $P$, level of statistical significance; QOL, quality of life; WHOQOLBREF, the World Health Organization Quality of Life Scale Brief version. 


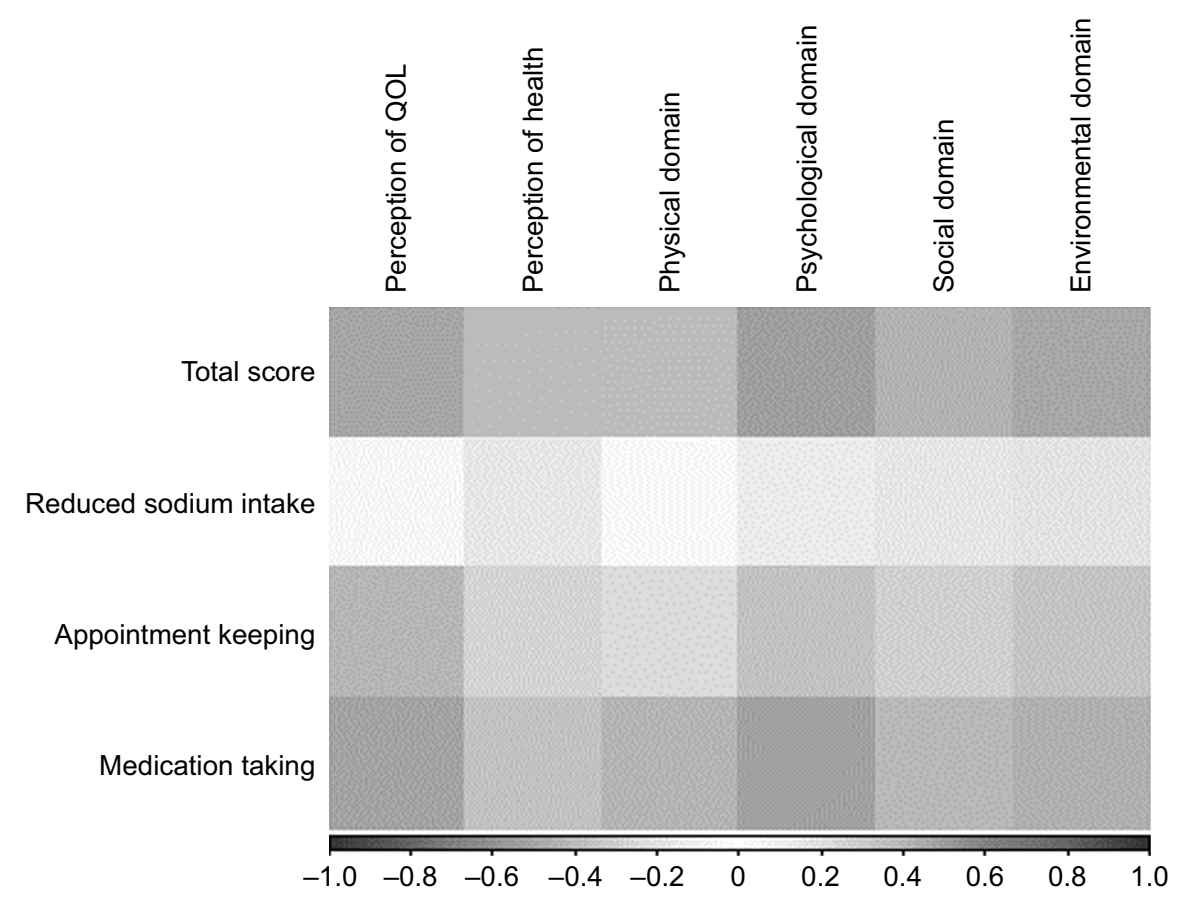

Figure I The correlation coefficient between the analyzed variables of the WHOQOL-BREF.

Abbreviations: QOL, quality of life; WHOQOL-BREF, the World Health Organization Quality of Life Scale Brief version.

\section{Univariate analysis}

The influence of selected sociodemographic factors on adherence - quantitative factors

The association between selected quantitative sociodemographic features (age, duration of disease) and the total score of the HBQ questionnaire was analyzed. Since it was demonstrated that the total HBQ score is positively correlated with the age and duration of the disease, the frequency of breaking treatment recommendations also increases with age and the duration of the disease $(P<0.05)$. Moreover, the frequency of breaking treatment recommendations regarding "appointment keeping" positively correlate with the duration of the disease $(P<0.05)$, as do the results of the "taking medicines" subscale, which positively correlate with age and the duration of the disease $(P<0.05)$ (Table 3$)$.

\section{The influence of selected sociodemographic and} clinical factors on adherence - qualitative factors

The association between selected qualitative sociodemographic and clinical features and the total score and subsequent subscales of the HBQ questionnaire was analyzed. It was shown that single, divorced, and widowed people were more likely to break the general treatment recommendations $(P<0.001)$ and the "appointment keeping" $(P<0.001)$ than people in relationships. In addition, widowed patients broke recommendations on "medication taking" $(P<0.001)$ more often than people in relationships. When taking education into account, patients with secondary, primary, or no education broke more general recommendations regarding "appointment keeping" $(P=0.009)$ and "medication taking" $(P=0.001)$ more than people with a higher education. When analyzing the place of residence, patients living alone or in organized institutions were more likely to break the general recommendations $(P<0.001)$ and those regarding the "appointment keeping" $(P=0.11)$ and "medication taking" $(P=0.01)$ than those living with their family. Also, people who used polytherapy were more likely to break the general treatment recommendations than people using monotherapy $(P=0.041)$.

\section{Multivariate analysis}

The influence of selected sociodemographic factors on adherence - total score of the HBQ questionnaire

The linear regression model showed that the independent predictors of the total score for the HBQ questionnaire were $(P<0.05): 1)$ QOL in the environmental domain - each additional point lowered it by an average of 0.56 points and 2 ) education - higher education or higher vocational education lowered it by an average of 1.758 points as compared to basic or no education.

The $\mathrm{B}^{2}$ coefficient was $45.20 \%$ for this model, which means that $45.20 \%$ of the volatility of the total score was 
explained by variables taken into the model. The remaining $54.80 \%$ depended on variables not included in the model and on random factors (Table 4).

\section{The influence of selected sociodemographic factors} on adherence - "reduced sodium intake" subscale of the $\mathrm{HBQ}$ questionnaire

The linear regression model illustrated that the independent predictors of the total score for the "reduced sodium intake" of the HBQ questionnaire were $(P<0.05)$ : 1$)$ QOL in the physical domain - each additional point raised it by an average of 0.143 points and 2) QOL in the environmental domain - each additional point lowered it by an average of 0.254 points.

Table 4 Multivariate analyses of chosen variables for a total score of the HBQ

\begin{tabular}{|c|c|c|c|c|}
\hline \multirow{2}{*}{$\begin{array}{l}\text { Variable } \\
\text { Perception of QOL }\end{array}$} & \multirow{2}{*}{$\frac{B^{2}}{-0.124}$} & \multicolumn{2}{|l|}{$95 \% \mathrm{Cl}$} & \multirow{2}{*}{$\begin{array}{l}P \text {-value } \\
0.828\end{array}$} \\
\hline & & -1.252 & 1.003 & \\
\hline Perception of health & -0.328 & -1.229 & 0.574 & 0.473 \\
\hline Physical domain & 0.057 & -0.331 & 0.445 & 0.772 \\
\hline Psychological domain & -0.015 & -0.498 & 0.469 & 0.952 \\
\hline Social domain & -0.058 & -0.357 & 0.241 & 0.701 \\
\hline Environmental domain & -0.56 & -0.997 & -0.122 & 0.013 \\
\hline Age, years & 0.021 & -0.089 & 0.131 & 0.708 \\
\hline Duration of disease, years & -0.03 & -0.108 & 0.048 & 0.446 \\
\hline \multicolumn{5}{|l|}{ Sex } \\
\hline Female & Ref. item & & & \\
\hline Male & 0.39 & -0.82 & 1.6 & 0.525 \\
\hline \multicolumn{5}{|l|}{ Marital status } \\
\hline Married/living together & Ref. item & & & \\
\hline Single/divorced & $1.74 \mid$ & $-0.46 I$ & 3.943 & 0.12 \\
\hline Widowed & 1.112 & -0.539 & 2.763 & 0.185 \\
\hline \multicolumn{5}{|l|}{ Education } \\
\hline None/primary & Ref. item & & & \\
\hline Secondary & -0.829 & -2.405 & 0.747 & 0.3 \\
\hline Vocational/higher & -1.758 & -3.481 & -0.034 & 0.046 \\
\hline \multicolumn{5}{|l|}{ Occupational activity } \\
\hline Employed & Ref. item & & & \\
\hline Retired & -1.712 & -3.449 & 0.026 & 0.053 \\
\hline Annuitant & -1.998 & -4.145 & 0.148 & 0.068 \\
\hline \multicolumn{5}{|l|}{ Place of residence } \\
\hline $\begin{array}{l}\text { Living alone/in an } \\
\text { organized institution }\end{array}$ & Ref. item & & & \\
\hline Living with family & -0.277 & -1.929 & 1.375 & $0.74 I$ \\
\hline \multicolumn{5}{|l|}{ Therapy } \\
\hline Monotherapy & Ref. item & & & \\
\hline Polytherapy & -1.254 & -3.35 & 0.842 & 0.239 \\
\hline
\end{tabular}

Abbreviations: $\mathrm{B}^{2}$, linear regression parameter; $\mathrm{HBQ}$, the Hill-Bone Compliance to High Blood Pressure Therapy Scale questionnaire; QOL, quality of life; Ref., referral.
The $\mathrm{B}^{2}$ coefficient was $22.61 \%$ for this model, which means that $22.61 \%$ of the volatility of the total score was explained by variables taken into the model. The remaining $74.39 \%$ depended on variables not included in the model and on random factors (Table 5).

The influence of selected sociodemographic factors on adherence - "appointment keeping" subscale of the HBQ questionnaire

The linear regression model did not show independent predictors on the "appointment keeping" subscale of the HBQ questionnaire $(P>0.05)$ (Table 6).

Table 5 Multivariate analyses of chosen variables for reduced sodium intake subscale of the $\mathrm{HBQ}$

\begin{tabular}{|c|c|c|c|c|}
\hline \multirow{2}{*}{$\begin{array}{l}\text { Variable } \\
\text { Perception of QOL }\end{array}$} & \multirow{2}{*}{$\begin{array}{l}\mathbf{B}^{2} \\
0.253\end{array}$} & \multicolumn{2}{|l|}{$95 \% \mathrm{Cl}$} & \multirow{2}{*}{$\frac{P \text {-value }}{0.22}$} \\
\hline & & -0.154 & 0.66 & \\
\hline Perception of health & -0.248 & -0.574 & 0.077 & 0.134 \\
\hline Physical domain & 0.143 & 0.003 & 0.283 & 0.045 \\
\hline Psychological domain & 0.065 & -0.11 & 0.239 & 0.465 \\
\hline Social domain & -0.022 & -0.13 & 0.086 & 0.692 \\
\hline Environmental domain & -0.254 & -0.412 & -0.096 & 0.002 \\
\hline Age, years & 0.008 & -0.031 & 0.048 & 0.677 \\
\hline Duration of disease, years & -0.005 & -0.033 & 0.023 & 0.718 \\
\hline \multicolumn{5}{|l|}{ Sex } \\
\hline Female & Ref. item & & & \\
\hline Male & 0.027 & -0.41 & 0.463 & 0.904 \\
\hline \multicolumn{5}{|l|}{ Marital status } \\
\hline Married/living together & Ref. item & & & \\
\hline Single/divorced & 0.222 & -0.573 & 1.016 & 0.582 \\
\hline Widowed & 0.379 & -0.216 & 0.975 & 0.21 \\
\hline \multicolumn{5}{|l|}{ Education } \\
\hline None/primary & Ref. item & & & \\
\hline Secondary & 0.108 & -0.46 & 0.677 & 0.707 \\
\hline Vocational/higher & 0.041 & -0.581 & 0.663 & 0.896 \\
\hline \multicolumn{5}{|l|}{ Occupational activity } \\
\hline Employed & Ref. item & & & \\
\hline Retired & -0.448 & -1.075 & 0.179 & 0.16 \\
\hline Annuitant & -0.03 & -0.805 & 0.744 & 0.939 \\
\hline \multicolumn{5}{|l|}{ Place of residence } \\
\hline $\begin{array}{l}\text { Living alone/in an } \\
\text { organized institution }\end{array}$ & Ref. item & & & \\
\hline Living with family & 0.114 & -0.482 & 0.71 & 0.706 \\
\hline \multicolumn{5}{|l|}{ Therapy } \\
\hline Monotherapy & Ref. item & & & \\
\hline Polytherapy & -0.026 & -0.782 & 0.731 & 0.947 \\
\hline
\end{tabular}

Abbreviations: $\mathrm{B}^{2}$, linear regression parameter; $\mathrm{HBQ}$, the Hill-Bone Compliance to High Blood Pressure Therapy Scale questionnaire; QOL, quality of life; Ref., referral. 
Table 6 Multivariate analyses of chosen variables for appointment keeping subscale of the HBQ

\begin{tabular}{|c|c|c|c|c|}
\hline \multirow{2}{*}{$\begin{array}{l}\text { Variable } \\
\text { Perception of QOL }\end{array}$} & \multirow{2}{*}{\begin{tabular}{|l|}
$\mathbf{B}^{2}$ \\
-0.213
\end{tabular}} & \multicolumn{2}{|l|}{$95 \% \mathrm{Cl}$} & \multirow{2}{*}{$\frac{P \text {-value }}{0.164}$} \\
\hline & & -0.514 & 0.088 & \\
\hline Perception of health & -0.112 & -0.352 & 0.129 & 0.36 \\
\hline Physical domain & 0.069 & -0.035 & 0.172 & 0.192 \\
\hline Psychological domain & 0 & -0.129 & 0.129 & 0.996 \\
\hline Social domain & -0.007 & -0.087 & 0.073 & 0.862 \\
\hline Environmental domain & -0.087 & -0.204 & 0.029 & 0.141 \\
\hline Age, years & -0.004 & -0.033 & 0.025 & 0.79 \\
\hline Duration of disease, years & -0.007 & -0.028 & 0.014 & 0.51 \\
\hline \multicolumn{5}{|l|}{ Sex } \\
\hline Female & Ref. item & & & \\
\hline Male & 0.086 & -0.237 & 0.409 & 0.598 \\
\hline \multicolumn{5}{|l|}{ Marital status } \\
\hline Married/living together & Ref. item & & & \\
\hline Single/divorced & 0.544 & -0.044 & 1.132 & 0.069 \\
\hline Widowed & 0.22 & -0.221 & 0.66 & 0.326 \\
\hline \multicolumn{5}{|l|}{ Education } \\
\hline None/primary & Ref. item & & & \\
\hline Secondary & 0.068 & -0.353 & 0.488 & 0.752 \\
\hline Vocational/higher & -0.174 & -0.634 & 0.286 & 0.457 \\
\hline \multicolumn{5}{|l|}{ Occupational activity } \\
\hline Employed & Ref. item & & & \\
\hline Retired & -0.139 & -0.603 & 0.324 & 0.554 \\
\hline Annuitant & -0.286 & -0.859 & 0.286 & 0.325 \\
\hline \multicolumn{5}{|l|}{ Place of residence } \\
\hline $\begin{array}{l}\text { Living alone/in an } \\
\text { organized institution }\end{array}$ & Ref. item & & & \\
\hline Living with family & -0.015 & -0.456 & 0.426 & 0.947 \\
\hline \multicolumn{5}{|l|}{ Therapy } \\
\hline Monotherapy & Ref. item & & & \\
\hline Polytherapy & 0.553 & -0.007 & 1.112 & 0.053 \\
\hline
\end{tabular}

Abbreviations: $\mathrm{B}^{2}$, linear regression parameter; $\mathrm{HBQ}$, the Hill-Bone Compliance to High Blood Pressure Therapy Scale questionnaire; QOL, quality of life; Ref., referral.

The influence of selected sociodemographic factors on adherence - "medication taking" subscale of the $\mathrm{HBQ}$ questionnaire

The linear regression model showed that the independent predictors of the total score for the "medication taking" subscale of the HBQ questionnaire was $(P<0.05)$ : 1$)$ higher or higher vocational education lowered it by an average of 1.625 points as compared to basic or no education and 2) polytherapy lowered it by an average of 1.781 points.

The $\mathrm{B}^{2}$ coefficient was $42.81 \%$ for this model, which means that $42.81 \%$ of the volatility of the total score was explained by variables taken into the model. The remaining
Table 7 Multivariate analyses of chosen variables for medication taking subscale of the $\mathrm{HBQ}$

\begin{tabular}{|c|c|c|c|c|}
\hline \multirow{2}{*}{$\begin{array}{l}\text { Variable } \\
\text { Perception of QOL }\end{array}$} & \multirow{2}{*}{\begin{tabular}{|l|}
$\mathbf{B}^{2}$ \\
-0.165
\end{tabular}} & \multicolumn{2}{|l|}{$95 \% \mathrm{Cl}$} & \multirow{2}{*}{\begin{tabular}{|l|}
$P$-value \\
0.726
\end{tabular}} \\
\hline & & -1.09 & 0.761 & \\
\hline Perception of health & 0.032 & -0.708 & 0.772 & 0.932 \\
\hline Physical domain & -0.155 & -0.474 & 0.163 & 0.337 \\
\hline Psychological domain & -0.079 & -0.476 & 0.318 & 0.694 \\
\hline Social domain & -0.03 & -0.275 & 0.216 & 0.813 \\
\hline Environmental domain & -0.218 & -0.577 & 0.141 & 0.231 \\
\hline Age, years & 0.016 & -0.074 & 0.107 & 0.719 \\
\hline Duration of disease, years & -0.018 & -0.082 & 0.046 & 0.578 \\
\hline \multicolumn{5}{|l|}{ Sex } \\
\hline Female & Ref. item & & & \\
\hline Male & 0.227 & -0.716 & 1.27 & 0.583 \\
\hline \multicolumn{5}{|l|}{ Marital status } \\
\hline Married/living together & Ref. item & & & \\
\hline Single/divorced & 0.975 & -0.833 & 2.783 & 0.288 \\
\hline Widowed & 0.513 & -0.842 & 1.868 & 0.455 \\
\hline \multicolumn{5}{|l|}{ Education } \\
\hline None/primary & Ref. item & & & \\
\hline Secondary & -1.005 & -2.299 & 0.289 & 0.127 \\
\hline Vocational/higher & -1.625 & -3.04 & -0.21 & 0.025 \\
\hline \multicolumn{5}{|l|}{ Occupational activity } \\
\hline Employed & Ref. item & & & \\
\hline Retired & -1.124 & -2.551 & 0.302 & 0.121 \\
\hline Annuitant & -1.682 & -3.444 & 0.081 & 0.061 \\
\hline \multicolumn{5}{|l|}{ Place of residence } \\
\hline $\begin{array}{l}\text { Living alone/in an } \\
\text { organized institution }\end{array}$ & Ref. item & & & \\
\hline Living with family & -0.376 & -1.732 & 0.98 & 0.584 \\
\hline \multicolumn{5}{|l|}{ Therapy } \\
\hline Monotherapy & Ref. item & & & \\
\hline Polytherapy & $-1.78 \mid$ & -3.502 & $-0.06 \mid$ & 0.043 \\
\hline
\end{tabular}

Abbreviations: $\mathrm{B}^{2}$, linear regression parameter; $\mathrm{HBQ}$, the Hill-Bone Compliance to High Blood Pressure Therapy Scale questionnaire; QOL, quality of life; Ref., referral.

$57.19 \%$ depended on variables not included in the model and on random factors (Table 7).

\section{Discussion}

QOL is an important issue in older hypertensive patients. One of the most important factors determining QOL is a person's state of health, which determines a good level of psychosocial functioning. ${ }^{25,26} \mathrm{In}$ the literature, increasing attention has been devoted to the health-related quality of life (HRQOL) of chronically ill patients because the HRQOL can affect the person's attitude toward the disease, as well as the attitude to treatment, which includes the appropriate level of adherence. ${ }^{27,28}$ 
In our study, the research group consisted of 186 people who had been diagnosed with hypertension from 7 to 17 years and averaged 71.05 years of age. Considering the presence of comorbidities in our study, $54.84 \%$ of respondents had diabetes, $32.26 \%$ had hypercholesterolemia, nearly $30 \%$ suffered from coronary heart disease, and almost $20 \%$ had rheumatic diseases or renal failure. The literature emphasizes the negative impact of age on the prevalence of comorbidities and cardiovascular risk factors, and thus there is a decrease in the QOL and a poorer level of adherence to therapeutic recommendations. ${ }^{29,30}$ Wang et al ${ }^{31}$ conducted a study in a population of more than 51,000 people over 65 years of age that showed that the main factors contributing to nonadherence for taking antihypertensive drugs were comorbidities and decreased HRQOL.

Chronic diseases, including hypertension, have a negative impact on the QOL of the population. In our study, the average score for the perception of patients' QOL was 3.36 points ( $\mathrm{SD}=0.84$ points), which determines the QOL level between average and good. The results were similar in the patients' assessments of their own health; they assessed their health as average, with the best QOL scores obtained in the psychological domain, slightly worse scores in the environmental and social domains, and the worst scores in the physical domain. All domains demonstrated a reduction in QOL due to chronic diseases. Numerous scientific reports confirm the negative effect of hypertension on QOL as compared to the healthy population. ${ }^{32-36}$ In the study conducted by Wang et al, ${ }^{32}$ a lower QOL score in hypertensive patients in the physical domain and total QOL score was found, which is also presented in our study. Other authors investigating the population of hypertensive patients have reported a lower level of the total QOL score in comparison to persons with normotension. ${ }^{36}$ It has also been shown that lowering blood pressure values improves the patient's QOL. ${ }^{37}$ Some studies have illustrated that the QOL in hypertensive patients, as well as in people in the general population, decreases with age. ${ }^{38,39}$

The key to effective antihypertensive therapy is to adhere to the therapeutic recommendations of the entire medical team at each stage of treatment. In our study, the average scoring of the HBQ questionnaire was 20.39 points ( $\mathrm{SD}=4.31$ points) and ranged from 14 to 34 points; the higher the score, the lower level of adherence. We found that patients most often broke recommendations regarding appointment keeping. It should be emphasized that despite the significant correlations in QOL shown in univariate analyzes, only the QOL in the environmental domain affects total HBQ score in the multivariate analysis. So this is the most important, independent predictor of the HBQ score. It needs to be pointed out that this domain incorporates facets like: financial resources; freedom; physical safety and security; health and social care: accessibility and quality; home environment; opportunities for acquiring new information and skills; participation in and opportunities for recreation/leisure activities; physical environment (pollution/noise/traffic/ climate); and transport. ${ }^{21}$

The literature confirms that only every third patient with newly detected pre-hypertension applies for a control visit to conduct a full diagnosis. ${ }^{40-42}$ A satisfactory level of adherence in relation to hypertension is at least $80 \%{ }^{43}$ Recent studies show that the highest level of adherence is most often observed during hospitalization, when patients even reach $100 \%$. Unfortunately, this level is alarmingly low (nearly $64 \%$ ) in patients who take medication alone at home. ${ }^{44,45}$ Available data show that less than half of the patients return to the pharmacy for another dose of medication after only six months of treatment. ${ }^{46}$

The adherence level in our study was also affected by selected sociodemographic and clinical factors; the patient's age and duration of the disease also turned out to be significant. In the elderly patients and those who had suffered longer, a poorer adherence to therapeutic recommendations was observed. The reason for this phenomenon may have been the deterioration of the physical condition and numerous problems related to older age, which contribute to the omission of a specific dose of the drug. ${ }^{44,47}$ It was also shown that single, divorced, and widowed patients more often broke general recommendations and keeping appointments with a doctor than patients in relationships. In addition, patients living alone or in organized facilities were more likely to break general recommendations regarding keeping appointments and taking medications than those who lived with their families. This may be due to the support that patients receive from life partners since they pay more attention to their health because they are considering the spouse or partner. ${ }^{48,49}$

The level of adherence to therapeutic recommendations in our study was also affected by education. Namely, the patients with secondary, primary, or no education were more likely to break the general recommendations regarding keeping appointments and taking medications than patients with a higher education. However, Matschay et al ${ }^{50}$ state that higher education, family support, and high income do not always transfer to better adherence to therapy.

In our study, people who used polytherapy were more likely to break the general recommendations than people using monotherapy. This may be due to the number of tablets 
taken during a day. The data from pharmacy registers also confirm this relationship; patients receiving a drug in the form of a single combined preparation show a higher level of adherence than patients receiving the same drug, but in two or three separate preparations. ${ }^{51}$ Literature confirms that simplifying therapy through the use of a complex antihypertensive preparation significantly improves the patient's motivation to strictly adhere to a medical regimen. In such a situation, one can expect greater patient satisfaction and adherence in following the recommended therapy. The number of tablets taken and the dosing schedule of antihypertensive drugs affect the effectiveness of the therapy; using a long-acting combination of drugs provides a convenient way of dosing while reducing the number of tablets taken by the patient. ${ }^{52,53}$

In the case of all chronic diseases, including hypertension, it is required to undertake significant approaches including specialist diagnostics and to put efforts in the field of effective primary and secondary prevention. QOL and its every component is an important aspect in the treatment of hypertension. Treatment of hypertension with both pharmacological and non-pharmacological methods can reduce the risk of hypertension-related complications and prevent gradual deterioration of the patients' QOL in a long-term perspective. The correct choice of drugs can improve the QOL, increasing the opportunity for the expected level of adherence and optimal therapy for hypertension.

\section{Study limitations}

Although this research was carefully prepared, we are aware of its potential limitations and shortcomings. Namely, only a self-reported test identifying adherence was used in the present study. It should be noted that the cross-sectional design of this study can preclude causal interpretation of the obtained results. Also, the potential limitation is the fact that the study sample consisted of elderly hypertensive patients from a single outpatient center. Therefore, our findings should be carefully extrapolated to the multicenter or institutional studies.

\section{Practical implications}

Health care professionals should identify the strategies for increasing adherence in their daily practice. Based on our results, the lower level of QOL could be a marker of poor adherence to treatment recommendations in this group of patients thus the regular QOL assessment should be considered when planning treatment as a routine procedure with prognostic value. Growing evidence suggests that combining approaches that are tailored to address a patient's specific adherence barriers may equip hypertensive patients with the understanding and tools they need to successfully engage in medication adherence. Physicians must recognize that poor medication adherence contributes to suboptimal clinical benefits. Increasing adherence may have a greater effect on health than any improvement in specific medical treatments.

\section{Conclusion}

There is an association between QOL and adherence to therapeutic recommendations among hypertensive elderly patients. It has been concluded that with an increasing QOL, the level of adherence to therapeutic recommendations increases. The level of adherence is also affected by: 1) age (the older age, the worse adherence); 2) duration of the disease (the longer the duration of the disease, the worse adherence); 3) marital status (there is worse adherence in single, divorced, and widowed patients than in those living with a spouse or partner); 4) education (there is better adherence and cooperation with higher educated people); 5) place of residence (there is better adherence among patients living with the family); and 6) type of therapy (monotherapy has a more beneficial effect on adherence).

\section{Acknowledgments}

The certificated English language services were provided by an academic highly qualified native English speaker to ensure a proper language quality including syntax, spelling and grammar issues. This study was conducted under a research project funded by the Ministry of Science and Higher Education in Poland as a part of the statutory grant of the Wroclaw Medical University in Poland for maintaining the research potential (no ST.E020.17.050).

\section{Disclosure}

The authors report no conflicts of interest in this work.

\section{References}

1. Chwojnicki K, Wierucki $Ł$, Zagożdżon P, et al. Long-term mortality after stroke is higher than after myocardial infarction. Neurol Sci. 2016; 37(6):891-898.

2. Lewington S, Clarke R, Qizilbash N, et al. Age-specific relevance of usual blood pressure to vascular mortality: a meta-analysis of individual data for one million adults in 61 prospective studies. Lancet. 2002; 360(9349):1903-1913.

3. Mills KT, Bundy JD, Kelly TN, et al. Global disparities of hypertension prevalence and control: a systematic analysis of population-based studies from 90 countries. Circulation. 2016;134(6):441-450.

4. Lacruz ME, Kluttig A, Hartwig S, et al. Prevalence and incidence of hypertension in the general adult population. Medicine. 2015;94(22):e952. 
5. Kawecka-Jaszcz K, Pośnik-Urbańska A, Jankowski P. Prevalence of arterial hypertension in Poland - impact of gender. Arter Hypertens. 2007; 11:377-383.

6. Gaciong Z. Standards of diagnostic and therapeutic procedures in hypertension in various clinical situations. Guide GPs. 2008;11:68-73.

7. Garrison SR, Kolber MR, Korownyk CS, et al. Blood pressure targets for hypertension in older adults. Cochrane Database Syst Rev. 2017;8: CD011575.

8. Banegas JR, Segura J, Ruilope LM, et al. Blood pressure control and physician management of hypertension in hospital hypertension units in Spain. Hypertension. 2004;43(6):1338-1344.

9. Denker MG, Cohen DL. What is an appropriate blood pressure goal for the elderly: review of recent studies and practical recommendations. Clin Interv Aging. 2013;8:1505-1517.

10. Sabaté E, Project WA to LTT, Network GAI, et al [webpage on the Internet]. Adherence to long-term therapies: evidence for action; 2003. Available from: http://apps.who.int/iris/handle/10665/42682. Accessed July 2, 2018.

11. Abegaz TM, Shehab A, Gebreyohannes EA, Bhagavathula AS, Elnour AA. Nonadherence to antihypertensive drugs: A systematic review and meta-analysis. Medicine. 2017;96(4):e5641.

12. Vrijens B, Antoniou S, Burnier M, de La Sierra A, Volpe M. Current situation of medication adherence in hypertension. Front Pharmacol. 2017;8:100.

13. Yang F, Chen QW. Evaluation of frailty and influencing factors in old people in hospital institution: Evidence for a phenotype of frailty. Medicine. 2018;97(3):e9634.

14. Lenardt MH, Carneiro NH, Binotto MA, et al. Frailty and quality of life in elderly primary health care users. Rev Bras Enferm. 2016;69(3): 478-483.

15. Trevisol DJ, Moreira LB, Kerkhoff A, Fuchs SC, Fuchs FD. Healthrelated quality of life and hypertension: a systematic review and metaanalysis of observational studies. J Hypertens. 2011;29(2):179-188.

16. Brito DM, Araújo TL, Galvão MT, Moreira TM, Lopes MV. Quality of life and perception of illness among individuals with high blood pressure. Cad Saude Publica. 2008;24(4):933-940.

17. Chin YR, Lee IS, Lee HY. Effects of hypertension, diabetes, and/or cardiovascular disease on health-related quality of life in elderly Korean individuals: a population-based cross-sectional survey. Asian Nurs Res. 2014;8(4):267-273.

18. Barreto Mda S, Reiners AA, Marcon SS. Knowledge about hypertension and factors associated with the non-adherence to drug therapy. Rev Lat Am Enfermagem. 2014;22(3):491-498.

19. Zyoud SH, Al-Jabi SW, Sweileh WM, et al. Health-related quality of life associated with treatment adherence in patients with hypertension: a cross-sectional study. Int J Cardiol. 2013;168(3):2981-2983.

20. Czarnecka D, Jankowski P, Kopeć G, et al. Polish Forum for Prevention Guidelines on Hypertension: update 2017. Kardiol Pol. 2017;75(3): $282-285$.

21. The WHOQOL Group. Development of the World Health Organization WHOQOL-BREF quality of life assessment. The WHOQOL Group. Psychol Med. 1998;28(3):551-558.

22. Wolowicka I, Jaracz K. Polish version of the WHOQOL - WHOQOL 100 and WHOQOL BREEF. In: Quality of Life in Medical Sciences. Poznan, Poland: Poznan Medical University Publisher; 2001: 231-238.

23. Kim MT, Hill MN, Bone LR, Levine DM. Development and testing of the Hill-Bone Compliance to High Blood Pressure Therapy Scale. Prog Cardiovasc Nurs. 2000;15(3):90-96.

24. Uchmanowicz I, Jankowska-Polańska B, Chudiak A, SzymańskaChabowska A, Mazur G. Psychometric evaluation of the Polish adaptation of the Hill-Bone Compliance to High Blood Pressure Therapy Scale. BMC Cardiovasc Disord. 2016;16:87.

25. Degl'innocenti A, Elmfeldt D, Hofman A, et al. Health-related quality of life during treatment of elderly patients with hypertension: results from the Study on Cognition and Prognosis in the Elderly (SCOPE). J Hum Hypertens. 2004;18(4):239-245.
26. Katsi V, Kallistratos MS, Kontoangelos K, et al. Arterial hypertension and health-related quality of life. Front Psychiatry. 2017;8:270.

27. Megari K. Quality of life in chronic disease patients. Health Psychol Res. 2013;1(3):27.

28. Adams RJ. Improving health outcomes with better patient understanding and education. Risk Manag Healthc Policy. 2010;3:61-72.

29. Vrijens B, Vincze G, Kristanto P, Urquhart J, Burnier M. Adherence to prescribed antihypertensive drug treatments: longitudinal study of electronically compiled dosing histories. BMJ. 2008;336(7653): 1114-1117.

30. Bastos-Barbosa RG, Ferriolli E, Coelho EB, et al. Association of frailty syndrome in the elderly with higher blood pressure and other cardiovascular risk factors. Am J Hypertens. 2012;25(11):1156-1161.

31. Wang PS, Avorn J, Brookhart MA, et al. Effects of noncardiovascular comorbidities on antihypertensive use in elderly hypertensives. Hypertension. 2005;46(2):273-279.

32. Wang R, Zhao Y, He X, et al. Impact of hypertension on health-related quality of life in a population-based study in Shanghai, China. Public Health. 2009;123(8):534-539.

33. Bardage C, Isacson DG. Hypertension and health-related quality of life. An epidemiological study in Sweden. J Clin Epidemiol. 2001;54(2): 172-181.

34. Banegas JR, Guallar-Castillón P, Rodríguez-Artalejo F, et al. Association between awareness, treatment, and control of hypertension, and quality of life among older adults in Spain. Am J Hypertens. 2006;19(7): 686-693.

35. Li W, Liu L, Puente JG, et al. Hypertension and health-related quality of life: an epidemiological study in patients attending hospital clinics in China. J Hypertens. 2005;23(9):1667-1676.

36. Raskeliene V, Babarskiene MR, Macijauskiene J, et al. Impact of duration and treatment of arterial hypertension on health-related quality of life. Med Kaunas Lith. 2009;45:405-411.

37. Sung J, Woo JM, Kim W, Lim SK, Chung AS. Relationship between blood pressure variability and the quality of life. Yonsei Med J. 2014; 55(2):374-378.

38. Finestone AJ. Appropriate blood pressure for the "old-old" ( 85 years and older). Clin Interv Aging. 2014;9:1009-1010.

39. Rockwood MR, Howlett SE. Blood pressure in relation to age and frailty. Can Geriatr J. 2011;14(1):2-7.

40. Fiscella $\mathrm{K}$, Ogedegbe $\mathrm{G}, \mathrm{He} \mathrm{H}$, et al. Blood pressure visit intensification study in treatment: trial design. Am Heart J. 2015;170(6):1202-1210.

41. Miller AP, Navar AM, Roubin GS, Oparil S. Cardiovascular care for older adults: hypertension and stroke in the older adult. $J$ Geriatr Cardiol. 2016;13(5):373-379.

42. Stokes GS. Management of hypertension in the elderly patient. Clin Interv Aging. 2009;4:379-389.

43. Yusuff KB, Alabi A. Assessing patient adherence to anti-hypertensive drug therapy: can a structured pharmacist-conducted interview separate the wheat from the chaff? Int J Pharm Pract. 2007;15(4):295-300.

44. Lo SH, Chau JP, Woo J, Thompson DR, Choi KC. Adherence to antihypertensive medication in older adults with hypertension. $J$ Cardiovasc Nurs. 2016;31(4):296-303.

45. Gellad WF, Grenard JL, Marcum ZA. A systematic review of barriers to medication adherence in the elderly: looking beyond cost and regimen complexity. Am J Geriatr Pharmacother. 2011;9(1):11-23.

46. Simpson SH, Eurich DT, Majumdar SR, et al. A meta-analysis of the association between adherence to drug therapy and mortality. BMJ. 2006;333(7557):15.

47. Jin $\mathrm{H}$, Kim Y, Rhie SJ. Factors affecting medication adherence in elderly people. Patient Prefer Adherence. 2016;10:2117-2125.

48. Alhaddad IA, Hamoui O, Hammoudeh A, Mallat S. Treatment adherence and quality of life in patients on antihypertensive medications in a Middle Eastern population: adherence. Vasc Health Risk Manag. 2016;12:407-413.

49. Holt EW, Rung AL, Leon KA, Firestein C, Krousel-Wood MA. Medication adherence in older adults: a qualitative study. Educ Gerontol. 2014;40(3):198-211. 
50. Matschay A, Turostowska R. Assessment of quality of cooperation between physicians and patients in treatment of arterial hypertension in a population of women and men. Med News. 2013;82:294-302.

51. Dezii CM. A retrospective study of persistence with single-pill combination therapy vs. concurrent two-pill therapy in patients with hypertension. Manag Care. 2000;9(9 Suppl):2-6.
52. Peacock E, Krousel-Wood M. Adherence to antihypertensive therapy. Med Clin North Am. 2017;101(1):229-245.

53. Canbakan B. Rational approaches to the treatment of hypertension: drug therapy-monotherapy, combination, or fixed-dose combination? Kidney Int Suppl. 2013;3(4):349-351.

\section{Publish your work in this journal}

Patient Preference and Adherence is an international, peer-reviewed, open access journal that focuses on the growing importance of patient preference and adherence throughout the therapeutic continuum. Patient satisfaction, acceptability, quality of life, compliance, persistence and their role in developing new therapeutic modalities and compounds to optimize clinical outcomes for existing disease states are major areas of interest for the journal. This journal has been accepted for indexing on PubMed Central. The manuscript management system is completely online and includes a very quick and fair peer-review system, which is all easy to use. Visit http://www. dovepress.com/testimonials.php to read real quotes from published authors.

\footnotetext{
Submit your manuscript here: http://www.dovepress.com/patient-preference-and-adherence-journal
} 